\title{
A glance at molecular mechanisms underlying cisplatin-induced nephrotoxicity and possible renoprotective strategies: a narrative review
}

Bashar Adi Wahyu Pandhita, ${ }^{1}$ Deliana Nur Ihsani Rahmi, ${ }^{1}$ Nielda Kezia Sumbung, ${ }^{1}$ Bernardino Matthew Waworuntu, ${ }^{1}$ Regina Puspa Utami, ${ }^{1}$ Melva Louisa, ${ }^{2}$ Vivian Soetikno ${ }^{2}$

pISSN: 0853-1773 • elSSN: 2252-8083 https://doi.org/10.13181/mji.v28i3.2690 Med J Indones. 2019;28:292-9

Received: March 06, 2018

Accepted: May 16, 2019

\section{Authors' affiliations:}

${ }^{1}$ Faculty of Medicine, Universitas Indonesia, Jakarta, Indonesia, ${ }^{2}$ Department of Pharmacology and Therapeutics, Faculty of Medicine, Universitas Indonesia, Jakarta, Indonesia

\section{Corresponding author:}

Vivian Soetikno

Department of Pharmacology and Therapeutics, Faculty of Medicine,

Universitas Indonesia, Jalan Salemba

6, Senen, Central Jakarta 10320, DKI

Jakarta, Indonesia

Tel/Fax: +62-21-31930481

E-mail: vivian_09st@yahoo.com

\begin{abstract}
Cisplatin is a platinum-based drug that is usually used for the treatment of many carcinomas. However, it comes with several devastating side effects, including nephrotoxicity. Cisplatin toxicity is a very complex process, which is exacerbated by the accumulation of cisplatin in renal tubular cells via passive diffusion and transportermediated processes. Once cisplatin enters these cells, it induces the formation of reactive oxygen species that cause cellular damage, including DNA damage, inflammation, and eventually cell death. On a small scale, these damages can be mitigated by cellular antioxidant defense mechanism. However, on a large scale, such as in chemotherapy, this defense mechanism may fail, resulting in nephrotoxicity. The current article reviews the molecular mechanisms underlying cisplatin-induced nephrotoxicity and possible renoprotective strategies to determine novel therapeutic interventions for alleviating this toxicity.
\end{abstract}

KEYWORDS cisplatin, kidney, oxidative stress, kidney injury
Cisplatin is an anticancer drug that has a highly efficacious for treating various types of cancers, such as head and neck, ovarian, cervical, and non-small cell lung cancers. However, the side effects of cisplatin are very severe, with one of them being nephrotoxicity. Approximately a quarter of patients treated with cisplatin develop nephrotoxicity with symptoms such as low glomerular filtration rate and low levels of serum minerals, such as potassium and magnesium. ${ }^{1}$ A study conducted at the Dharmais Cancer Hospital in Indonesia demonstrated that out of the 88 patients with cancer who received cisplatin chemotherapy, nephrotoxicity occurred in $34.1 \%$ and $51.8 \%$ patients after 4 and 6 cycles, respectively. ${ }^{2}$ The mechanism underlying cisplatin-induced nephrotoxicity is a very complex process involving various pathways, including DNA damage, oxidative stress, caspase activation, and inflammation. However, the exact mechanisms underlying nephrotoxicity is still unclear as there are many chicken-and-egg situations that need further clarification. ${ }^{1,3}$ This review was aimed to explain various mechanisms underlying cisplatin-induced nephrotoxicity and possible renoprotective strategies to pave the way for novel therapeutic interventions to alleviate cisplatin-induced nephrotoxicity.

MEDLINE, EMBASE, PubMed, and ISI Web of Science were searched for relevant articles. The proportion of free and paid articles was $83 \%$ and $17 \%$, respectively.

\section{Role of oxidative stress in cisplatin-induced nephrotoxicity}

For decades, cisplatin has been shown to produce oxidative stress. A research conducted by Pourahmad et $\mathrm{al}^{4}$ shows that the administration of cisplatin causes a decline in the mitochondrial membrane potential. 
However, the administration of an antioxidant can attenuate such damage, suggesting that the damage occurs due to the excessive production of reactive oxygen species (ROS). There is also a decrease in the activity of the pro-apoptotic protein caspase-3 after the administration of antioxidants butylated hydroxytoluene and dimethylsulfoxide. A comparatively less amount of damage occurred when the mitochondrial permeability transition pore was sealed. Moreover, the administration of cytochrome P450 2E1 (CYP2E1) and endocytosis inhibitors suggest that the production of ROS is caused by several mechanisms such as metal destruction by cytochrome P450, disruption of the mitochondrial electron transfer chain, and lysosomal involvement. ${ }^{4}$ In another study assessing the mitochondria, Zsengellér et $\mathrm{al}^{5}$ explained that cisplatin-induced nephrotoxicity is characterized by an increase in ROS and a decrease in cytochrome c oxidase (COX) enzyme activity. COX is an important enzyme in the electron transfer chain involved in energy production. A decrease in this enzyme's activity suggests that cisplatin administration induces structural and functional damages in the mitochondria. Moreover, a decrease in the mitochondrial crosssectional area was observed in cisplatin-induced nephrotoxicity. ${ }^{5}$ Zhang et $\mathrm{al}^{6}$ demonstrated that cisplatin depletes glutathione (GSH) storage in the mitochondria. The incubation of a renal slice in cisplatin resulted in a marked decrease by 33\% in GSH after 15 min and a peak decrease of $27 \%$ (normal value) after 180 min. In addition, lipid peroxidation increased by 1.8-fold of the normal marker value. This explains that cisplatin mainly elucidates its action by targeting and destroying the mitochondria as shown by a decrease in the mitochondrial enzyme activity and protein content. However, this research fails to identify the mitochondrial target and the cause of toxicity. ${ }^{6}$ In line with previous results, we have also demonstrated that cisplatin administration can increase malondialdehyde levels and decrease GSH activity in rat kidney tissues.7 Moreover, the study conducted by Kruidering et $\mathrm{al}^{8}$ has demonstrated that the enzymatic activity of the electron transport chain decreases when porcupine tubular cells are incubated with cisplatin. This incubation subsequently results in ATP depletion. The mechanism underlying ROS formation is a complex process. The inhibition of electron transport chain complex I increases ROS production. However, cisplatin also impairs the cell's antioxidant system as it not only affects metabolism enzymes but also other enzymes such as $\mathrm{Cu} / \mathrm{Zn}$-superoxide dismutase (SOD) and catalase. ${ }^{8}$ Another research by Santos et $\mathrm{al}^{9}$ also demonstrates that cisplatin increases glutathione disulfide content and lipid peroxidation level and reduces SOD level and cellular antioxidant function. In addition, mitochondrial damage is indicated by an increase in the carbonyl group marker. This marker represents the cleaving of protein, and its increase indicates damage to mitochondrial proteins. Subsequently, all enzymatic activities in the mitochondria slow down, including those in the citric acid cycle. The level of an important enzyme of the citric acid cycle, aconitase, has been shown to decrease, thereby impairing ATP production. Furthermore, the oxidation of the iron-sulfur bond of aconitase releases $\mathrm{Fe}^{2+}$ and $\mathrm{H}_{2} \mathrm{O}_{2}$, initiating the Fenton reaction, releasing the hydroxyl radical. This overall process contributes to the oxidative stress on mitochondria. ${ }^{9}$

Cisplatin treatment also reduces mitochondrial calcium uptake. The administration of cisplatin can increase intracellular calcium level. Increased intracellular calcium levels caused by cisplatin are due to cisplatin decreasing calcium uptake in the mitochondria, not because of increased extracellular calcium influx. However, administering an intracellular calcium chelator did not increase the calcium level. Therefore, these results suggest that cisplatin meddles with calcium homeostasis, thereby significantly increasing the intracellular calcium level. When intracellular calcium level drastically increases, the mitochondria also uptakes calcium into its matrix, disrupting the electron transport chain, which results in the production of ROS.10

\section{Role of DNA damage in cisplatin-induced nephrotoxicity}

Another mechanism underlying cisplatin-induced toxicity is the disruption in DNA. Once cisplatin enters the cell, it is activated by the displacement of a chloride atom by a water molecule. This reaction produces an electrophile, which binds to the N7 center of the purine residues of DNA, preventing the division of cell and thereby triggering the apoptotic pathway. ${ }^{11}$ According to Basnakian et al, $^{12}$ cisplatin-induced toxicity via DNA damage is caused by the activity of deoxyribonuclease I (DNase I). In their study, DNase I-deficient mice showed higher resistance to cisplatininduced injury. Following cisplatin administration, mortality in DNase I-deficient mice decreased with 
increased kidney function biomarker levels (blood urea nitrogen and creatinine). Moreover, tubular damage was also attenuated with lesser number of tubular cells undergoing necrosis. This is because DNase I is responsible for DNA fragmentation following DNA damage. Evidence suggests that DNA fragmentation plays an important role in cisplatin-induced nephrotoxicity as the inhibition of DNA fragmentation can attenuate cisplatin damage. ${ }^{12}$ In addition, Pabla et al ${ }^{13}$ explained that DNA damage response is mediated by the ataxia-telangiectasia and Rad3-related (ATR) and checkpoint kinase (Chk)-2 genes. Reportedly, after cisplatin administration, the ataxia-telangiectasiamutated (ATM) and DNA-dependent protein kinase (DNA-PK) genes are inactivated; moreover, ATR activation occurs, which leads to the phosphorylation of Chk1 and Chk2. Subsequently, Chk2 activates p53, which induces apoptotic cascade. Moreover, the role of the ATM, ATR, and DNA-PK genes is to indicate DNA damage. These genes will then induce effector proteins, such as Chk1 and Chk2. If DNA damage is extensive, then the effector proteins are unable to fix the damage, resulting in the activation of p53 for the cell to undergo apoptosis. ${ }^{13}$

\section{Role of inflammation in cisplatin-induced nephrotoxicity}

Cisplatin nephrotoxicity is not only related to direct cellular toxicity but also to inflammation. Many researchers have found that renal epithelial cells injury that is induced by cisplatin causes the release of damage-associated molecular patterns (DAMPs). Tolllike receptor -4 (TLR4) is then activated by DAMP, which induces the production of chemokines and cytokines, which upregulate adhesion molecules and attract inflammatory cells, including neutrophils and T cells, to the injured site. ${ }^{14,15}$ One of the inflammatory cytokines is tumor necrosis factor- $\alpha$ (TNF- $\alpha$ ), which has a significant role in infectious and inflammatory diseases. Kelly et $\mathrm{al}^{16}$ and Deng et $\mathrm{al}^{17}$ have demonstrated that the renal expression of TNF- $\alpha$ increases in mice with cisplatininduced nephrotoxicity. In line with the previous studies, Ramesh et al, ${ }^{18}$ have also shown that mice treated with TNF-a inhibitors are less prone to cisplatininduced renal dysfunction with less histologic evidence of renal injury compared with mice treated without TNF- $\alpha$ inhibitors. The significance of TNF- $\alpha$ was also tested in TNF- $a$-knockout mice; in these mice, less renal injury and higher survival rates were observed following cisplatin injection compared with wild-type mice. ${ }^{18,19}$ In the previous study, it could be shown that in cisplatininduced acute kidney injury (AKI) model, the levels of pro-inflammatory cytokines, TNF- $\alpha$, and interleukin (IL)-6, as well as the level of the transcription factor nuclear factor-kappa B (NFkB) increase in renal tissues, whereas the level of the anti-inflammatory cytokine IL10 decrease. ${ }^{20}$

ROS, NFKB activation, and p38 mitogen-activated protein kinase (MAPK) activation play a significant role in the production of TNF-a following the administration of cisplatin. Researchers have found that dimethylthiourea, salicylate, and p38 inhibitors can reduce TNF production and nephrotoxicity in cisplatin-treated mice. ${ }^{19,21}$ TNF-receptor (TNFR1/p55 and TNFR2/p75) mediate the biological activities of TNF- $a$. TNFR1 mediates most of TNF- $\alpha$ cytotoxic and pro-inflammatory actions, ${ }^{22,23}$ while TNFR2 mediates the actions related to cisplatin nephrotoxic effects of TNF- $\alpha$, when there is a deficiency of TNFR1. ${ }^{24}$

Another factor that can exacerbate cisplatininduced nephrotoxicity is TLRs, which are pattern recognition receptors that function to detect proteins, foreign organisms, and nucleic acids. They can initiate the innate and adaptive immune response when they sense foreign invaders. They also detect and respond to alarmins or DAMPs, which are associated with tissue injury. ${ }^{15,25}$

Lipopolysaccharide (LPS) is an agonist of TLR4 that can induce $\mathrm{AKI}$ at high doses or exacerbate kidney injury at low doses. ${ }^{26}$ This implies that LPS and cisplatin exhibit synergism when causing kidney injury, and this effect is dependent on both TLR4 and TNF-a. ${ }^{27-29}$ Zhang et al. have reported that wild-type mice have a more significant cisplatin-induced renal dysfunction compared with TLR4-knockout mice. ${ }^{14,30}$ TLR4 is also related to cytokines, which in turn affect inflammation. Reportedly, the levels of cytokines in TLR4-knockout mice are significantly lower in serum, kidney, and urine than those in wild-type mice. p38 aActivation (essential in cisplatin-induced TNF- $\alpha$ production) in TLR4-knockout mice is lower than that in wild-type mice. ${ }^{21}$ Researchers have found that TLR4 acts as a sensor for cisplatin-induced epithelial injury. The nephrotoxic effects of cisplatin are mediated by parenchymal TLR4 instead of myeloid TLR4. TLR4 thus activates p38 MAPK pathways and further increases the production of inflammatory cytokines. ${ }^{25,30}$ 


\section{Mechanical pathway of cisplatin-induced nephrotoxicity}

The recently proposed mechanism of cisplatininduced nephrotoxicity comprises several pathways that lead to cell death either by necrosis or apoptosis. In vitro, the type of cell death that occurs is affected by the concentration of cisplatin. Higher concentrations of cisplatin trigger necrosis whereas lower concentrations induce apoptosis. ${ }^{31}$ However, in vivo, cisplatin triggers both necrosis and apoptosis. ${ }^{32}$ Recently, we have also demonstrated that cisplatin administration increases the renal expression of $\mathrm{Bax} / \mathrm{BCl}-2$ protein ratio, which suggested an increase in apoptosis. ${ }^{20}$ Cisplatin-induced apoptosis is considered to be primarily mediated by the following three pathways: extrinsic pathway, which is activated by the binding of death receptors; intrinsic pathway, which focuses on the mitochondria; and endoplasmic reticulum (ER) stress pathway. ${ }^{25,32}$ Intrinsic pathway has been proposed to have the most important impact on cisplatin-induced cell apoptosis. In this pathway, mitochondria play an important role as they contain pro-apoptotic proteins of the $\mathrm{Bcl}-2$ protein family. The $\mathrm{Bcl}-2$ family comprises protein with both antiapoptotic and pro-apoptotic groups. The proapoptotic group of $\mathrm{Bcl}-2$ comprises not less than 12 proteins, some of which are Bax, Bak, Bok, Bik, Bad, Bid, and Bim, whereas the antiapoptotic group comprises 6 proteins, some of which are $\mathrm{BCl}-\mathrm{X}, \mathrm{BCl}-\mathrm{W}, \mathrm{Mcl}-1$, and $\mathrm{BCl}-2.25,33$ The proposed mechanism of the intrinsic pathway, which underlies cisplatin-induced toxicity, is through the activation of Bax and Bak protein. ${ }^{34}$ This activation disrupts the mitochondrial membrane by making it permeable and subsequently releasing cytochrome c, which then binds with apoptosis protease-activating factor-1. This resultant structure is called as an apoptosome, which induces caspase-9 activation. Caspase-9 plays the important role of an initiator in mitochondrial pathway as it triggers other caspases, which are important in further stages of the apoptotic pathway. ${ }^{33,34}$ Besides cytochrome c, mitochondria also release other apoptogenic factors, such as apoptosis-inducing factor (AIF) and Smac/Diablo. AIF has an important role in inducing apoptosis, including cisplatin-induced apoptosis. The inhibition of AIF results in resistance to cisplatin, suggesting that AIF plays an important role in initiating apoptosis. Meanwhile, Smac/Diablo induces apoptosis by inhibiting the function of apoptosis inhibitor. This inhibition leads to the activation of caspase cascade, resulting in apoptosis. Mechanistically, the intrinsic and extrinsic pathways depend on the mitochondria and on the regulation of several death receptors, respectively. The death receptors belong to the TNFR family and contain a death domain, which is important for inducing apoptosis.33,34 The members of this family include TNRF1 and Fas receptor. Reportedly, Fas, Fas ligand, and TNF-a mRNA levels increase after the administration of cisplatin both in vivo and in vitro, indicating that the cisplatin induces the activation of the death receptor pathway. ${ }^{25}$ Fas ligand plays an important role in activating caspase-8, which triggers the cascade of caspases such as caspase-3, -6 , and -7 , eventually leading to apoptosis. The role of Fas- and TNFR1-induced apoptosis has also been demonstrated in Fas- and TNFR1-deficient mice. Caspase- 8 activation was observed in both the mouse groups, suggesting that both Fas and TNFR1 are important for the activation of caspase- 8 and the apoptotic pathway. ${ }^{33}$ The third apoptotic pathway that is induced by cisplatin is the ER stress pathway. This pathway is triggered by an increase in the cystosolic calcium level and by the activation of calpain, a protease that is important for the activation of caspase-12. As cisplatin triggers protein accumulation and disturbs calcium homeostasis, the ER stress pathway is triggered, which consequently results in conformational changes in and/or the oligomerization of Bax and Bak in the ER membrane, resulting in the release of calcium ion. Calcium ions activate calpain, which cleaves procaspase-12 into caspase-12. Subsequently, caspase-12 triggers caspase cascade by inducing caspase- 9 and ultimately results in apoptosis. ${ }^{34}$

The activation of the apoptotic pathway by cisplatin has been linked to a tumor suppressor protein, p53. The first in vivo study conducted to examine the correlation between $\mathrm{p} 53$ and cisplatin has shown that p53-deficient mice develop resistance toward cisplatin. ${ }^{35}$ Moreover, it demonstrated that the inhibition of p53 using pifithrin-a suppresses the development of AKI. ${ }^{36,37}$ Another study has also demonstrated that the deletion of PUMA- $\alpha$-specific small interfering RNA inhibits cisplatin-induced tubular cell death. ${ }^{38}$ Reportedly, p53 induces cell arrest or cell death depending on the severity of the stress. $^{39}$ Its activation is correlated with DNA damage. As cisplatin triggers DNA damage, it induces ATR. Only ATR the proteins then phosphorylate and activate $\mathrm{p} 53$. The role of $\mathrm{p} 53$ in inducing apoptosis 
has been primarily noted in the intrinsic pathway; it triggers the activation of caspase-2, which then induces AIF and the Bax-mediated mitochondrial pathway. It also triggers the activation of the other pro-apoptotic agent PUMA- $\alpha$, which induces $\mathrm{BCl}-\mathrm{xl}$ that triggers Bax activation, resulting in the induction of apoptosis, more particularly the intrinsic pathway. Interestingly, although p53 seems to have a role in inducing apoptosis, it also triggers the production of p21, a cyclin-dependent kinase inhibitor, which has a cytoprotective effect. ${ }^{38,39}$ A recent study has shown that cytoplasmic p21 overexpression results in resistance to cisplatin in the initially sensitive cells. ${ }^{40}$ The main role of p21 is to initially inhibit apoptosis by antagonizing cyclin-dependent kinase 2 (CDK2). However, it also has been shown that CDK2 has a unique mechanism to halt this inhibitory effect of p21, indicating that the cytotoxic mechanism of cisplatin continues even after the induction of p21.40,41

\section{Cisplatin uptake and metabolism}

Cisplatin-induced nephrotoxicity is positively correlated with its accumulation in kidney tissues. ${ }^{42,43}$ Cisplatin enters the renal tubular cells through passive diffusion and transporter-mediated processes, resulting in its high accumulation. ${ }^{44} \mathrm{~A}$ transporter that is associated with cisplatin uptake is organic cation transporter 2 (OCT2); recently, copper transporter 1 (CTR1) has also been identified to be associated with cisplatin uptake. ${ }^{45}$ Jacobs et al ${ }^{46}$ were the first to report the renal secretion of cisplatin. They concluded this based on the observation that the renal clearance of free platinum exceeds the creatinine clearance in cisplatin-treated subjects. In fact, previous studies have concluded that the OCT system mediates the secretion of cisplatin as the administration of organic cationic compounds was found to decrease the renal accumulation of cisplatin as well as its renal toxicity. ${ }^{47-49} \mathrm{~A}$ more detailed study using opossum kidney epithelial cell line incubated with 100-mM cisplatin on the apical or basolateral side comprehensively confirmed the result of the aforementioned studies. ${ }^{44}$ This study demonstrated that the accumulation and basolateral-to-apical transport of cisplatin was mediated by the OCT system, which is localized to the basolateral side of the renal epithelial cells. However, out of two identified and assessed human OCTs, OCT2 was found to be the primary OCT of the human kidney that interacts with cisplatin. Other studies have also confirmed that cisplatin does not interact with other human OCTs, such as OCT1. Human OCT1 is the main OCT isoform in the liver. These findings may explain the organ-specific cisplatin toxicity in the kidneys. ${ }^{50-52}$ Meanwhile, Ishida et al $^{52}$ have demonstrated that CTR1 is implicated in cisplatin uptake in mutagenized yeast cells; moreover, they reported that mouse CTR1-knockout cell line exhibits higher resistance to cisplatin than the wild-type cell line.

High accumulation, however, is not the only factor causing cisplatin nephrotoxicity. Bird et al ${ }^{48}$ found that one of the cisplatin analogs, oxaliplatin, resulted in higher accumulation of platinum than cisplatin; however, its accumulation did not produce effects similar to those resulting from platinum accumulation from cisplatin. Therefore, it is suggested that the interaction of the drug with specific biomolecules of target organs is also responsible for nephrotoxicity. ${ }^{48}$

\section{Protective factors in cisplatin-induced nephrotoxicity}

Research by Yang et al $^{53}$ has demonstrated that autophagy can decelerate cell death due to cisplatin. Phosphoinositide 3-kinase $(\mathrm{PI} 3 \mathrm{~K})$ is an important enzyme in autophagosome formation. When a $\mathrm{PI} 3 \mathrm{~K}$ inhibitor is administered, it increases the production and activation of caspase. ${ }^{53}$ This was also demonstrated in the study by Takahashi et al, ${ }^{54}$ where mice deficient in autophagy-related protein 5 were used. Kidney function in these mice was significantly lower compared with that in controls. Furthermore, autophagy has been found to protect cell from apoptosis by destroying defective mitochondria. Autophagy is a protective mechanism of the cell to get rid of the defective and ROS-producing mitochondria. ${ }^{53}$ Recently, Zhang et $\mathrm{al}^{55}$ have demonstrated that autophagy is inhibited by the enzyme protein kinase $c \delta$ (PKC $\delta$ ). The administration of cisplatin activates this enzyme, which subsequently induces the mechanistic target of rapamycin and prevents autophagy. The importance of autophagy in cellular defense against cisplatin-induced toxicity was observed when the activity of PKC $\delta$ was inhibited. Mice with defective PKC $\delta$ expressions show better renal function. This shows that autophagy is an important defense mechanism in cisplatin-induced nephrotoxicity. ${ }^{54}$ This evidence was further strengthened by the results of 
the study by Zhao et al, ${ }^{56}$ in which mitophagy was found to play a protective role in cisplatin-induced tubular cell injury. Moreover, the knockdown of PTEN-induced kinase 1/Parkin gene was found to inhibit cisplatin-induced mitophagy. However, this resulted in increased mitochondrial dysfunction, and the overexpression of the gene was found to reduce mitochondrial dysfunction. They also showed that overexpression of this gene can inhibit cisplatininduced apoptosis in renal tubular cells. ${ }^{55}$

Another factor that exhibits a protective effect on cisplatin-induced nephrotoxicity is nuclear factor erythroid 2-related factor 2 ( $\mathrm{Nrf} 2$ ). This factor activated in under oxidative stress, and it regulates many genes, such as heme oxygenase 1, SOD2 and SOD3, thioredoxin, and glutamate-cysteine ligase, which are responsible for redox homeostasis. Wilmes et $a^{57}$ demonstrated that $\mathrm{Nrf} 2$ gene activity increases cisplatin-induced nephrotoxicity, which subsequently increases Nrf2 gene end product, which balances the oxidative stress in cells.

In summary, many types of research have provided significant insights into the molecular signaling pathways, which are responsible for cisplatin-induced nephrotoxicity (Figure 1). Till date, cisplatin-induced nephrotoxicity has been largely avoided by adequate pretreatment hydration and chloride diuresis; nevertheless, these approaches of cisplatin-induced nephrotoxicity were mostly partial. Therefore, revealing the molecular signaling pathways will facilitate future research that focuses on renoprotective strategies.
Figure 1. Proposed molecular mechanisms of cisplatin-induced nephrotoxicity

\section{Conflict of Interest}

Melva Louisa and Vivian Soetikno are editorial board members but were not involved in the review or decision process for the article.

\section{Acknowledgment}

We thank Dr. Wawaimuli Arozal, M. Biomed., Ph.D, Department of Pharmacology and Therapeutics, Faculty of Medicine, University of Indonesia, for helping us in the review.

\section{Funding Sources}

This study was funded by PITTA grant.

\section{REFERENCES}

1. Yang $\mathrm{Y}$, Liu H, Liu F, Dong Z. Mitochondrial dysregulation and protection in cisplatin nephrotoxicity. Arch Toxicol. 2014;88(6):1249-56.

2. Prasaja Y, Sutandyo N, Andrajati R. Incidence of cisplatininduced nephrotoxicity and associated factors among cancer patients in Indonesia. Asian Pac J Cancer Prev. 2015;16(3):111722.

3. Walker RJ, Endre ZH. Cellular mechanism of drug nephrotoxicity. In: Alpern RJ, Moe OR, Caplan MJ. Seldin and Giebisch's the kidney. $5^{\text {th }}$ ed. 2013; Philadelphia: Saunders Elsevier. p.2889-932.

4. Pourahmad J, Hosseini MJ, Eskandari MR, Shekarabi SM, Daraei B. Mitochondrial/lysosomal toxic cross-talk plays a key role in cisplatin nephrotoxicity. Xenobiotica. 2010;40(11):763-71.

5. Zsengellér ZK, Ellezian L, Brown D, Horváth B, Mukhopadhyay $P$, Kalyanaraman $B$, et al. Cisplatin nephrotoxicity involves mitochondrial injury with impaired tubular mitochondrial enzyme activity. J Histochem Cytochem. 2012;60(7):521-9.

6. Zhang JG, Lindup WE. Role of mitochondria in cisplatin-induced oxidative damage exhibited by rat renal cortical slices. Biochem Pharmacol. 1993;45(11):2215-22.

7. SariSD, Maknun LU, Louisa M, Estuningtyas A, Soetikno V. Effects of nanocurcumin against cisplatin-induced nephrotoxicity in rats. Adv Sci Lett. 2017;23(7):6823-7.

8. Kruidering $M$, Van de Water B, de Heer E, Mulder GJ, Nagelkerke $J F$. Cisplatin-induced nephrotoxicity in porcine proximal tubular 
cells: mitochondrial dysfunction by inhibition of complexes I to IV of the respiratory chain. J Pharmacol Exp Ther. 1997;280(2):638-49.

9. Santos NA, Catão CS, Martins NM, Curti C, Bianchi ML, Santos AC. Cisplatin-induced nephrotoxicity is associated with oxidative stress, redox state unbalance, impairment of energetic metabolism and apoptosis in rat kidney mitochondria. Arch Toxicol. 2007;81(7):495-504.

10. Kawai Y, Nakao T, Kunimura N, Kohda Y, Gemba M. Relationship of intracellular calcium and oxygen radicals to cisplatin-related renal cell injury. J Pharmacol Sci. 2006;100(1):65-72.

11. Dasari S, Tchounwou PB. Cisplatin in cancer therapy: molecular mechanism of action. Eur J Pharmacol. 2014;740:364-78.

12. Basnakian AG, Apostolov EO, Yin X, Napirei M, Mannherz HG, Shah SV. Cisplatin nephrotoxicity is mediated by deoxyribonuclease I. J Am Soc Nephrol. 2005;16(3):697-702.

13. Pabla N, Huang S, Mi QS, Daniel R, Dong Z. ATR-Chk2 signaling in $\mathrm{p} 53$ activation and DNA damage response during cisplatininduced apoptosis. J Biol Chem. 2007;283(10):6572-83.

14. Zhang B, Ramesh G, Norbury CC, Reeves WB. Cisplatin-induced nephrotoxicity is mediated by tumor necrosis factor-a produced by renal parenchymal cells. Kidney Int. 2007;72(1):37-44.

15. Gluba A, Banach M, Hannam S, Mikhailidis DP, Sakowicz A, Rysz J. The role of Toll-like receptors in renal diseases. Nat Rev Nephrol. 2010;6(4):224-35.

16. Kelly KJ, Meehan SM, Colvin RB, Williams WW, Bonventre JV. Protection from toxicant-mediated renal injury in the rat with anti-CD54 antibody. Kidney Int. 1999;56(3):922-31.

17. Deng J, Kohda Y, Chiao H, Wang Y, Hu X, Hewitt SM, et al. Interleukin-10 inhibits ischemic and cisplatin-induced acute renal injury. Kidney Int. 2001;60(6):2118-28.

18. Ramesh G, Reeves WB. TNF-a mediates chemokine and cytokine expression and renal injury in cisplatin nephrotoxicity. J Clin Invest. 2002;110(6):835-42.

19. Mahgoub E, Kumaraswamy SM, Kader KH, Venkataraman B, Ojha S, Adeghate E, et al. Genipin attenuates cisplatin-induced nephrotoxicity by counteracting oxidative stress, inflammation, and apoptosis. Biomed Pharmacother. 2017;93:1083-97.

20. Soetikno V, Sari SD, Maknun LU, Sumbung NK, Rahmi DN, Pandhita BA, et al. Pre-treatment with curcumin ameliorates cisplatin-induced kidney damage by suppressing kidney inflammation and apoptosis in rats. Drug Res. 2018;69(2):75-82.

21. Ramesh G, Reeves WB. Salicylate reduces cisplatin nephrotoxicity by inhibition of tumor necrosis factor-a. Kidney Int. 2004;65(2):490-8.

22. Ramesh G, Reeves WB. p38 MAP kinase inhibition ameliorates cisplatin nephrotoxicity in mice. Am J Physiol Renal Physiol. 2005;289(1):F166-74.

23. Barbara JA, Smith WB, Gamble JR, Van Ostade X, Vandenabeele $P$, Tavernier J, et al. Dissociation of TNF- $\alpha$ cytotoxic and proinflammatory activities by $\mathrm{p} 55$ receptor- and p75 receptorselective TNF-a mutants. EMBO J. 1994;13(4):843-50.

24. Locksley RM, Killeen N, Lenardo MJ. The TNF and TNF receptor superfamilies: integrating mammalian biology. Cell. 2001;104(4):487-501.

25. Ramesh G, Reeves WB. TNFR2-mediated apoptosis and necrosis in cisplatin-induced acute renal failure. Am J Physiol Renal Physiol. 2003;285(4):F610-8.

26. Kono H, Rock KL. How dying cells alert the immune system to danger. Nat Rev Immunol. 2008;8(4):279-89.

27. Cunningham PN, Wang Y, Guo R, He G, Quigg RJ. Role of Toll-like receptor 4 in endotoxin-induced acute renal failure. J Immunol. 2004;172(4):2629-35.

28. Ramesh G, Zhang B, Uematsu S, Akira S, Reeves WB. Endotoxin and cisplatin synergistically induce renal dysfunction and cytokine production in mice. Am J Physiol Renal Physiol. 2007;293(1):F325-32.

29. Ramesh G, Kimball SR, Jefferson LS, Reeves WB. Endotoxin and cisplatin synergistically stimulate TNF- $\alpha$ production by renal epithelial cells. Am J Physiol Renal Physiol. 2007;292(2):F812-9.

30. Zhang B, Ramesh G, Uematsu S, Akira S, Reeves WB. TLR4 signaling mediates inflammation and tissue injury in nephrotoxicity. J Am Soc Nephrol. 2008;19(5):923-32.

31. Tsung A, Klune JR, Zhang X, Jeyabalan G, Cao Z, Peng X, et al. HMGB1 release induced by liver ischemia involves Toll-like receptor 4 dependent reactive oxygen species production and calcium-mediated signaling. J Exp Med. 2007;204(12):2913-23.

32. Lieberthal W, Triaca V, Levine J. Mechanism of death induced by cisplatin in proximal tubular epithelial cells: apoptosis vs. necrosis. Am J Physiol. 1996;270 (4):F700-8.

33. Hong JY, Kim GH, Kim JW, Kwon SS, Sato EF, Cho KH, et al. Computational modeling of apoptotic signaling pathways induced by cisplatin. BMC Syst Biol. 2012;6:122.

34. Tsuruya K, Ninomiya T, Tokumoto M, Hirakawa M, Masutani K, Taniguchi $M$, et al. Direct involvement of the receptor-mediated apoptotic pathways in cisplatin-induced renal tubular cell death. Kidney Int. 2003;63(1):72-82.

35. Wei Q, Dong G, Yang T, Megyesi J, Price PM, Dong Z. Activation and involvement of p53 in cisplatin-induced nephrotoxicity. Am J Physiol Renal Physiol. 2007;293(4):F1282-91.

36. Tsuruya K, Yotsueda H, Ikeda H, Taniguchi M, Masutani K, Hayashida $\mathrm{H}$, et al. Involvement of p53-transactivated Puma in cisplatin-induced renal tubular cell death. Life Sci. 2008;83(1516):550-6.

37. Zhang D, Liu Y, Wei Q, Huo Y, Liu K, Liu F, et al. Tubular p53 regulates multiple genes to mediate AKI. J Am Soc Nephrol. 2014;25(10):2278-89.

38. Follis AV, Chipuk JE, Fisher JC, Yun MK, Grace CR, Nourse A, et al. PUMA binding induces partial unfolding within $B C L-x L$ to disrupt p53 binding and promote apoptosis. Nat Chem Biol. 2013;9(3):163-8.

39. di Pietro A, Koster R, Boersma-van Eck W, Dam WA, Mulder $\mathrm{NH}$, Gietema JA, et al. Pro- and anti-apoptotic effects of p53 in cisplatin-treated human testicular cancer are cell contextdependent. Cell Cycle. 2012;11(24):4552-62.

40. Hodeify R, Tarcsafalvi A, Megyesi J, Safirstein RL, Price PM. Cdk2-dependent phosphorylation of p21 regulates the role of Cdk2 in cisplatin cytotoxicity. Am J Physiol Renal Physiol. 2011;300(5):F1171-9.

41. Kawai Y, Tainuchi S, Okahara S, Nakamura M, Gemba M. Relationship between cisplatin or nedaplatin-induced nephrotoxicity and renal accumulation. Biol Pharm Bull. 2005;28(8):1385-8.

42. Esteban-Fernández D, Verdaguer JM, Ramírez-Camacho R, Palacios MA, Gómez-Gómez MM. Accumulation, fractionation, and analysis of platinum in toxicologically affected tissues after cisplatin, oxaliplatin, and carboplatin administration. J Anal Toxicol. 2008;32(2):140-6.

43. Kröning R, Lichtenstein AK, Nagami GT. Sulfur-containing amino acids decrease cisplatin cytotoxicity and uptake in renal tubule epithelial cell lines. Cancer Chemother Pharmacol. 2000;45(1):43-9.

44. Endo T, Kimura O, Sakata M. Carrier-mediated uptake of cisplatin by the OK renal epithelial cell line. Toxicology. 2000; 146(2-3):187-95.

45. Pabla N, Murphy RF, Liu K, Dong Z. The copper transporter Ctr1 contributes to cisplatin uptake by renal tubular cells during cisplatin nephrotoxicity. Am J Physiol Renal Physiol. 2009;296(3):F505-11.

46. Jacobs C, Kalman SM, Tretton M, Weiner MW. Renal handling of cis-diamminedichloroplatinum (II). Cancer Treat Rep. 1980;64(12):1223-6.

47. Osman NM, Litterst CL. Effect of probenecid and $\mathrm{N}$ '-methylnicotinamide on renal handling of cisdichlorodiammineplatinum-II in rats. Cancer Lett. 1983;19(1):10711.

48. Bird JE, Walser MM, QuebbemannAJ. Protective effect of organic cation transport inhibitors on cis-diamminedichloroplatinum- 
induced nephrotoxicity. J Pharmacol Exp Ther. 1984;231(3):7528.

49. Klein J, Bentur Y, Cheung D, Moselhy G, Koren G. Renal handling of cisplatin: interactions with organic anions and cations in the dog. Clin Invest Med. 1991;14(5):388-94.

50. Gorboulev V, Ulzheimer JC, Akhoundova A, Ulzheimer-Teuber I, Karbach U, Quester S, et al. Cloning and characterization of two human polyspecific organic cation transporters. DNA Cell Biol. 1997;16(7):871-81.

51. Ciarimboli G, Ludwig T, Lang D, Pavenstäd H, Koepsell H, Piechota HJ, et al. Cisplatin nephrotoxicity is critically mediated via the human organic cation transporter 2. Am J Pathol. 2005; 167(6):1477-84.

52. Ishida S, Lee J, Thiele DJ, Herskowitz I. Uptake of the anticancer drug cisplatin mediated by the copper transporter $\mathrm{Ctr} 1$ in yeast and mammals. Proc Natl Acad Sci U S A. 2002;99(22):14298-302.

53. Yang C, Kaushal V, Shah SV, Kaushal GP. Autophagy is associated with apoptosis in cisplatin injury to renal tubular epithelial cells. Am J Physiol Renal Physiol. 2008;294(4):F77787.

54. Takahashi A, Kimura T, Takabatake $\mathrm{Y}$, Namba T, Kaimori J, Kitamura $\mathrm{H}$, et al. Autophagy guards against cisplatin-induced acute kidney injury. Am J Pathol. 2012;180(2):517-25.

55. Zhang D, Pan J, Xiang X, Liu Y, Dong G, Livingston MJ, et al. Protein kinase $c \delta$ suppresses autophagy to induce kidney cell apoptosis in cisplatin nephrotoxicity. J Am Soc Nephrol. 2017;28(4):1131-44.

56. Zhao C, Chen Z, Xu X, An X, Duan S, Huang Z, et al. Pink1/ Parkin-mediated mitophagy play a protective role in cisplatin induced renal tubular epithelial cells injury. Exp Cell Res. 2017;350(2):390-7.

57. Wilmes A, Bielow C, Ranninger C, Bellwon P, Aschauer L, Limonciel $A$, et al. Mechanism of cisplatin proximal tubule toxicity revealed by integrating transcriptomics, proteomics, metabolomics and biokinetics. Toxicol In Vitro. 2015;30(1 Pt A):117-27. 